\title{
Espaços de trabalho para profissionais da informação: segunda parte - 2005-2007
}

\author{
Work spaces for information professionals in Brazil: second part
}

\author{
Miriam Vieira da Cunha (1) y Romario Antunes Silva (2)
}

(1) Departamento de Ciência da Informação, Universidade Federal de Santa Catarina, 88040-410

Florianópolis Brasil.mcunha@cin.ufsc.br (2) romarioantunes@gmail.com

\begin{abstract}
Resumen
Segunda parte de la investigación que tiene el objetivo de conocer y caracterizar las ofertas de empleo para profesionales de la información disponibles en sitios específicos y en listas de discusión en Internet, entre enero de 2005 y mayo de 2007. Utiliza la técnica de análisis de contenido de Bardin (2004) y tiene los siguientes criterios de análisis: fecha del anuncio, fuente de información, tipo de profesional, ciudad, formación y función solicitadas. Los resultados hasta el momento (mayo 2007) evidencian que la mayoría de las ofertas son para bibliotecarios y auxiliares y se concentran en la ciudad de São Paulo.
\end{abstract}

Palabras clave: Profesional de la información. Perfil profesional. Brasil.

\section{Introdução}

Esta é a segunda parte de uma pesquisa que tem o apoio do CNPq - Conselho Nacional de Desenvolvimento Científico e Tecnológico brasileiro iniciada em janeiro de 2005 devendo ser concluída em março de 2008. Os resultados aqui apresentados referem-se ao período que vai de janeiro de 2005 a maio de 2007 e incorporam os dados relativos à primeira parte da pesquisa (Cunha, 2006).

A idéia de estudar este tema -os perfis e os papéis do profissional da informação- nasceu de uma confluência de interesses -por um lado de minha prática inicial como bibliotecária em instituições brasileiras, francesas, de Moçambique e do Cabo Verde e, por outro lado, de minha prática de ensino e de pesquisa. Neste sentido, minha reflexão traz uma "marca" da minha passagem pela prática profissional. É um olhar vivido inicialmente através da prática. Este olhar com "duas caras", se podemos falar assim, tem vantagens e desvantagens. A maior vantagem talvez seja estudar o vivenciado. A desvantagem - o estar muito próxima do objeto de reflexão.

\begin{abstract}
Second part of a research project that intends to characterize the job offers for information professionals in Brazilian Internet sites and discussion lists, between January 2005 and May 2007. It uses Bardin's (2004) technique of content analysis and considers the following criteria: date of offer, source of information, type of professional, city, professional education and function. The results until now demonstrate that most of the offers are for librarians and library assistants in the city of São Paulo.
\end{abstract}

Keywords: Information Professional. Professional profile. Brazil.

Falar do profissional da informação, um tema tão discutido nos últimos dez anos significa tentar entender os ambientes onde se inserem estes profissionais, as mudanças do contexto que estamos vivenciando, um contexto de incertezas, de mutações, de relações internacionais complexas, de crises de sistemas políticos, de exclusão social e de violência. Mudamos de século, mudamos de milênio e é difícil entender para onde vamos. As possibilidades são imensas, mas as ameaças também. Acreditávamos que as facilidades da informática com suas inúmeras possibilidades nos proporcionariam mais tempo livre, mas a maioria das pessoas que trabalham nunca trabalharam tanto enquanto outros estão subempregados ou não conseguem trabalho.

Nunca houve tantos profetas e nunca houve tanta incerteza com o futuro do planeta. Tentamos, com nossas pequenas partes de estudo do mundo - com nossos olhares fragmentados da realidade- entender um pouco deste mundo fazer conexões, criar pontes. Mesmo com todas as conexões possíveis atualmente, nosso olhar é fragmentado, é sempre imperfeito, é pessoal, é às vezes contraditório, traz nossa marca, nos- 
sa cultura, nossa vivência. Enfim, nosso pensar é sempre provisório. Nossa fala reflete o pensar dos outros, reflete nossas leituras, nossas discussões, nosso fazer em sala de aula, nossos autores preferidos. Enfim, pretendemos através dos resultados de nossa pesquisa, fazer algumas reflexões sobre os profissionais da informação no Brasil.

Avanços consideráveis nos processos de comunicação da informação em todas as suas formas tem sido a tônica das mudanças, nos últimos trinta anos. Transformações históricas e tecnológicas repercutem, de forma particular, no campo das atividades de informação. Elas se traduzem em ameaças e questionamentos, e na necessidade de redesenhar as características das áreas de conhecimento e do fazer humanos.

Estas transformações criam novas necessidades e vêm alterando nossos paradigmas. Estamos começando a viver o que Browning (2002) chamou de "era das bibliotecas sem paredes para livros sem páginas". As tecnologias estão criando novas formas de informação e comunicação, bem como a cultura e os comportamentos decorrentes deste cenário.

$\mathrm{Na}$ era da globalização econômica, a informação é onipresente em todos os setores da vida humana. Essencial à vida das organizações, ela exerce um papel econômico e estratégico fundamental (ADBS, 2000).

A emergência da Internet como meio de acesso à informação, o desenvolvimento de redes eletrônicas e o acesso fácil à informação está levando a um aumento sem precedentes da independência dos usuários nas suas buscas, e em conseqüência, ao desaparecimento de algumas formas de mediação.

Com a crescente difusão das tecnologias informacionais e das habilidades necessárias para usá-las e desenvolvê-las, as linhas entre tecnologias de conteúdo e acesso tornam-se indistintas. Como resultado deste fenômeno, os limites entre as profissões ligadas à informação são cada vez mais tênues. Mas, não é só entre as profissões ligadas à informação que acontece esta "diluição" de fronteiras. Na realidade, os limites entre grupos profissionais são cada vez mais fluidos e indistintos, tornando-se mais difícil para qualquer grupo justificar a sua "jurisdição" (1) (no sentido que Abbott, 1988, dá a este termo) sobre outros. No caso dos bibliotecários, o fenômeno da "desintermediação" ou a idéia que cada vez mais informação é acessível via Internet, causa insegurança a estes profissionais. Entretanto, é necessário lembrar que a complexidade crescente dos ambientes informacionais demanda, continuamente, interfaces de pesquisa mais poderosas, o que, por sua vez, exige dos bibliotecários novas habilidades e competências.

As transformações da sociedade do conhecimento estão levando os profissionais da informação a redefinir seus papéis nos espaços tradicionais de atuação. Ao mesmo tempo que as tarefas de trabalho com informação estão mais complexas, esta redefinição não resultou no fortalecimento das profissões clássicas da informação, abrindo este campo para profissionais de outras áreas que trabalham em espaços diferenciados, muitas vezes em equipes interdisciplinares. Estes novos espaços de trabalho criam novas relações entra as profissões e possibilitam, em alguns casos, o rompimento das suas fronteiras.

A explosão da comunicação por meio da Internet e a percepção da informação como recurso estratégico levam cada vez mais pessoas a trabalhar com fontes de informação. Este movimento, ao mesmo tempo que cria tensões traz também novas oportunidades de alianças neste espaço interprofissional. O conjunto destes movimentos, tensões e alianças forma um novo campo de competência ou uma nova "jurisdição profissional" (Abbott, 1988).

Num contexto de necessidades complexas e diversificadas a Internet se apresenta como uma tela rica, mas fragmentada de informações que cresce em uma velocidade exponencial. Nos últimos anos têm surgido profissionais preocupados em "dar sentido" às informações da rede, em avaliar e recuperar os conteúdos da rede.

No Brasil, a disseminação das ofertas para profissionais da informação é dispersa e reduzida. Uma investigação feita anteriormente (Cunha, 1998) mostra que os jornais de grande circulação são, no nosso país, os veículos que mais divulgam estas ofertas. Entretanto, o baixo número de anúncios divulgados nestes meios, nos leva a crer que eles são divulgados de outras formas, como na Internet.

$\mathrm{Na}$ realidade, a rede tem sido um instrumento privilegiado de divulgação de ofertas de emprego, nos últimos 5 anos. (Arévallo, 2000). Esta difusão de postos de trabalho se faz através de sites específicos e listas de discussão da área.

\section{Análise dos resultados}

Esta pesquisa teve como objetivo conhecer e caracterizar as ofertas de trabalho para profissionais da informação disponíveis na Internet e difundidas em sites específicos e listas de discussão, entre janeiro de 2005 e maio de 2007. Utilizou a técnica de análise de conteúdo de 
Bardin (2004) e teve os seguintes critérios de análise: fonte de informação, tipo de profissional, cidade, tipo de instituição, formação, experiência profissional e função solicitadas.

É necessário lembrar que o termo "profissional da informação" cobre um campo de atividades bastante extenso, mais ou menos específico de acordo com os atores que participam destas atividades. Começou a ser empregado nos anos 80 para designar os profissionais que, segundo a Classificação Brasileira de Ocupações (2002):

disponibilizam informação em qualquer suporte; gerenciam unidades como bibliotecas, centros de documentação, centros de informação e correlatos, além de redes e sistemas de informação. Tratam tecnicamente e desenvolvem recursos informacionais; disseminam informação com o objetivo de facilitar o acesso e geração do conhecimento; desenvolvem estudos e pesquisas; realizam difusão cultural; desenvolvem ações educativas. Podem prestar serviços de assessoria e consultoria.

Para esta pesquisa foram selecionadas todas as ofertas que no nome do profissional ou no descritivo das suas funções evidenciasse trabalho com informação (ou seja bibliotecários, documentalistas, gestores de informação, analistas de informação, auxiliares de biblioteca, arquivistas e museólogos, entre outros).

Os sites analisados foram selecionados em função dos seguintes critérios: credibilidade, difusão de ofertas para profissionais da informação, e atualização.

A partir destes critérios os sites analisados foram:

- CATHO ONLINE: www.catho.com.br

- INFOHOME: www.ofaj.com.br

- BIBLIOTECÁRIAS: www.bibliotecarias.com.br

- BUMERAN: http://www.bumeran.com.br

As listas de discussão foram selecionadas em função de sua credibilidade e por difundir ofertas para profissionais da informação. Foram analisadas as seguintes listas:

- IBICT: Instituto Brasileiro de Informação Científica e Tecnológica www.bibvirtual.com.br

- IASI: Instituto para Inclusão na Sociedade da Informação www.iasi.org.br

- ABECIN: Associação Brasileira de Educação em Ciência da Informação www.abecin.org.br

- Das Associações de Bibliotecários;

- Do Conselho Regional de Biblioteconomia CRB 14 www.crb14.org.br

Do Curso de Biblioteconomia da UFSC biblio_ufsc@grupos.com.br
No Brasil, a evolução do campo de atividades da informação e de seus profissionais, no sentido de uma abertura e diversificação de seus espaços ainda é tímida, como se pode comprovar a partir dos dados apresentados a seguir.

Entre janeiro de 2005 e abril de 2007, foram divulgados nos sites e listas de discussão analisados, 1265 ofertas para profissionais de informação. A grande maioria, ou seja $80 \%$ solicita bibliotecários. A seguir aparecem as ofertas para auxiliares de biblioteca (6\%); os arquivistas representam $5 \%$.

A demanda por auxiliares de biblioteca se justifica, no nosso entender, por dois motivos: 1) seria a "confusão de limites entre o trabalho do bibliotecário e de seu auxiliar" (DANNER, 1998); 2) por razões econômicas - se o auxiliar pode executar o trabalho do profissional, é mais barato contratar um auxiliar.

Os resultados demonstram que os profissionais da informação mais procurados continuam sendo duas categorias das clássicas "três marias", para usar uma expressão cara a Johann Smit (1994), ou seja, os bibliotecários, os arquivistas sendo que os museólogos, até o presente momento não aparecem nas ofertas analisadas.

Esta concentração de demandas de bibliotecários se origina, no nosso entender, da legislação profissional brasileira. É necessário ressaltar que no Brasil, para trabalhar em uma biblioteca, o profissional deve ter feito um curso de graduação em Biblioteconomia. Esta formação é a única que permite a inscrição em um dos Conselhos de Biblioteconomia, instituições que regulamentam a profissão no Brasil (Brasil. Decreto 56726,1995$)(2)$

Além disso, cerca de $4 \%$ das ofertas solicitam, em um mesmo anúncio indiferentemente bibliotecários ou arquivistas. A título de comparação, nas ofertas brasileiras analisadas por Cunha, em 1998, 10,7\% solicitavam, indiferentemente um arquivista ou um bibliotecário. Este tipo de oferta, no nosso entender, pode ter dois significados:

- O empregador desconhece a área e, por esta razão "arrisca".

- O empregador não sabe que profissional quer, e, então solicita todos. Este tipo de reflexão foi feito por Cunha (1998) quando analisou os anúncios para profissionais da informação divulgados na mídia francesa e brasileira.

Com relação à formação, $62 \%$ solicitam uma formação em Biblioteconomia; $28 \%$ um profissional especializado com formação superior, sem indicar qual; $1,4 \%$ em Arquivologia; e 1,6\% em Arquivologia ou Biblioteconomia. Tudo leva 
a crer que, embora solicite, na maioria dos casos um bibliotecário, o empregador não relaciona este profissional à sua formação específica, o que pode significar um desconhecimento da mesma.

O que se compreende a partir destes dados é que, no Brasil, o profissional solicitado na maioria das unidades de informação continua sendo o bibliotecário. Na realidade, embora as universidades brasileiras comecem a apresentar uma diversificação de cursos na área de estudos da informação, com formações em Gestão da Informação, Sistemas de Informação, Ciência da Informação e Administração da Informação, entre outros, a Biblioteconomia continua sendo o curso mais visível, com 35 escolas no país. Os cursos de Arquivologia são apenas 7, os de Gestão da Informação 3 e os de Museologia dois (ABECIN, 2007).

No que se refere ao tipo de instituição, $40 \%$ das instituições identificadas que demandam um profissional da informação são públicas. Este resultado contrasta com a pesquisa que identificou o perfil dos profissionais da informação dos estados de Santa Catarina (Cunha et al., 2004) e do Rio Grande do Sul (Cunha et al., 2007) onde a maioria trabalha em instituições privadas.

Com relação ao conhecimento de línguas, apenas $15 \%$ solicita esta competência, sendo que a imensa maioria solicita o inglês. Tudo indica que grande parte dos pesquisadores consideram que os profissionais solicitados conhecem línguas e, por esta razão não é necessário explicitar esta informação nas ofertas. Na realidade atual de globalização e domínios das redes, o conhecimento de línguas é fundamental, conforme enfatizado por Tomael \& Alvarenga (2000), Marchiori (1996) e Montalli (1997) entre outros.

No que se refere à experiência profissional cerca de $43 \%$ das ofertas analisadas solicitam esta informação. A maioria demanda experiência em informática, fundamental para profissionais da informação no mundo atual.

São Paulo aparece como a cidade que mais solicita profissionais da informação. Isto não é surpresa pois esta cidade, além de ser a mais populosa, detém o maior Produto Interno Bruto brasileiro. Neste sentido, é lógico que concentre o maior número de ofertas. A seguir aparecem as cidades do Rio de Janeiro, e Brasília. O Rio de Janeiro, antiga capital federal é a cidade mais importante, em termos de desenvolvimento econômico, depois de São Paulo. Brasília, além da grande demanda de profissionais para postos do governo, têm atraído nos últimos anos, empresas de serviço que solicitam profissionais com competências em informação.

\section{Conclusão}

Esta pesquisa representa a fotografia de um momento preciso, em um ambiente em permanente evolução. Com relação à pluralidade de profissionais solicitados em $4 \%$ das ofertas, pesquisas de Baptista (2004), Cronin, Stiffler \& Day (1993) e Moore (1987), mencionam a falta de consenso dos empregadores com relação ao perfil do profissional que buscam. Além disso, os resultados tendem a demonstrar a falta de distinção existente entre as diferentes profissões da informação, com ênfase nos bibliotecários e arquivistas.

Com relação a esta relativa indefinição do perfil profissional, aos espaços de atuação comuns ou não perfeitamente identificados, Mueller (1989, p.69) aponta uma "solução possível" ou seja uma formação a partir da associação entre profissões afins:

Tal associação poderia se dar no sistema de formação profissional, com o estabelecimento de uma estrutura que permitisse movimentação não só no sentido vertical, como hoje existe, de bacharelado para mestrado e doutorado em uma mesma carreira, mas entre carreiras. Isto é, pessoas com formação básica diversa poderiam cursar os demais níveis da estrutura de formação profissional de quaisquer das áreas afins, com reconhecimento legal. Haveria então não apenas a classe bibliotecária, mas uma classe de profissionais da informação, da qual os bibliotecários fariam parte

Além disso, esta investigação corrobora resultado de pesquisas anteriores, como a de Tarapanoff (1997) ressaltando a demanda do bibliotecário nas unidades de informação.

$\mathrm{Na}$ realidade, apesar das mutações e da reorganização do espaço de trabalho, das novas parcerias, o campo informacional no Brasil ainda mostra resistência à abertura, com poucas alterações. Podemos concluir que as oportunidades de trabalho da informação no nosso país continuam dominadas pelos profissionais "clássicos". Os dados demonstram ainda que o "profissional tipo" solicitado por meio de sites específicos e listas de discussão na Internet entre janeiro de 2005 e abril de 2007 é um bibliotecário com formação em Biblioteconomia y com experiência em informática para trabalhar na cidade de São Paulo.

O que se evidencia, a partir do resultado da análise é que, apesar de privilegiar um profissional clássico, os empregadores, em muitos casos, não distinguem o tipo de profissional que querem. Esta falta de distinção é, em nosso entender, resultado das mutações dos espaços de trabalho. Para concluir é possível afirmar que, embora estamos vivenciando um momento 
de transformação no mundo laboral, no Brasil, o espaço dos profissionais da informação ainda é percebido como um espaço para profissionais tradicionais. Neste sentido, o conflito e a luta pela jurisdição da área, no nosso país é ainda incipiente.

\section{Notas}

(1) "Quando reivindica uma jurisdição, uma profissão exige da sociedade que reconheça sua estrutura cognitiva através de direitos exclusivos; a jurisdição não é apenas uma cultura, mas uma estrutura social. Estes direitos exclusivos podem incluir o monopólio da prática e de pagamentos públicos, direitos de disciplina, de trabalho, controle do treinamento profissional, do recrutamento e do licenciamento, para mencionar apenas alguns." (Abbott, 1998, tradução nossa).

(2) Este decreto informa que os Conselhos de Biblioteconomia tem como finalidade "orientar, disciplinar e supervisionar a regulamentação do exercício da profissão de bibliotecário e contribuir para o desenvolvimento profissional." (Brasil, Decreto 56726, 1965).

\section{Referências}

Abbott, A. (1988) The system of professions: an essay of division of expert labour. Chicago: The University of Chicago Press, 1988.

ABECIN (2007). Associação Brasileira de Educação em Ciência da Informação. URL: <www.abecin.org.br>. Consultado: 2007-05-01

ADBS (2000) Documentaliste d'aujourd'hui et de demain. URL: <www.adbs.fr>. Consultado: 2007-05-20.

Arévalo, J. A. (2000). Características del comportamiento del mercado de trabajo en Biblioteconomía, Archivística y Documentación, bienio 98/99. // Anales de Documentación. 3 (2000), 9-24.

Baptista, S.G. (2004). As oportunidades de trabalho existentes na Internet na área de construção de páginas de unidades de informação. // Baptista; Mueller (2004). Profissional da Informação: o espaço de trabalho. Brasilia: Tesaurus, 2004. 224-241.

Bardin, L. (2004) Analise de conteúdo. Lisboa: Edições 70, 2004.

Browning (2002). Libraries without walls for books without pages. URL: <www.wired.com/wired>. Consultado: 2007-05-10.

Brasil. Ministério do Trabalho e Emprego. (2002). Classificação Brasileira de Ocupações. CBO2002. URL: <http://www.mtecbo.gov.br/index.htm>. Consultado: 2007-04-30.

Cronin, B. Stiffler, M, Day, D. (1993). The emergent market for information professionals: educational opportunities and implications. // Library Trends. 42:2 (Fall 1993) 257276.

Cunha, M. V. (1998) L'émergence des nouveaux professionnels de l'information: fonctions, compétences, marché. Etude comparée des situations brésilienne et française, Tese. (Doutorado em Informação Científica e Técnica). Paris: Conservatoire National des Arts et Métiers, 1998. Tesis doctoral.

Cunha, M.V. (2006). Espacios de trabajo para profesionales de la información en Brasil: resultados preliminares. // XI IBERSID: Zaragoza, out.2006.
Cunha, M. F. V.; Silva, C. C. M.; Kill, C. F. . (2007) Perfil do bibliotecário formado pela Universidade Federal do Rio Grande do Sul. // Informação \& Sociedade. Estudos. 17 (2007) 1-10.

Cunha, M. F. V.; Pereira, M. C.; Guimaraes, C.; Silva, C. C. M. (2004). O bibliotecário formado pela Universidade Federal de Santa Catarina: perfil profissional. // Perspectivas em Ciência da Informação. 9:2 (2004) 182-195.

Danner, R.A. (1998). Redefining a profession. // Law Library Journal 90:3 (1998),315-356.

Dowbor (2001). O que acontece com o trabalho. São Paulo: SENAC, 2001.

Marchiori, P.(1996). Que profissional queremos formar para o século XXI. // Informação \& Informação. 1:1 (1996), 27-34.

Montalli, K. (1997). Perfil do profissional da informação tecnológico e empresarial. // Ciência da Informação, 26:3 (1997) 290-295.

Moore, N. (1987). The emerging markets for librarians and information workers. Boston Spa: The British Library, 1987. (Library and information research report no.56).

Mueller, S. P. M. (1989). Reflexões sobre a formação profissional para a Biblioteconomia e sua relação com as demais profissões da informação. Trans-In-Formação. // 1:2 (1989) 175-186.

Smit, J. W. (1994). Eu, bibliotecário, rg xxx e cpf yyy, trabalho em arquivo ou museu...algum problema?. // Revista Palavra-Chave. 8 (1994) 12-13.

Tarapanoff, K. (1997). Perfil do profissional da informação no Brasil. Brasília: IEL, 1997.

Tomael, M.I.; Alvarenga, G.M. (2000). Profissional da informação: espaço de atuação em empresas industriais. /I Perspectivas em Ciência da Informação. 5:1 (2000) 8190. 